\title{
Neuere Literatur zu Humanismus und Gelehrsamkeit im Spanien des 16. Jahrhunderts
}

Strosetzki, Christoph

First published in:

Romanistisches Jahrbuch 32 (1981), 260-285

ISSN: 0080-3898, 1613-0413

(C) 1982 Walter de Gruyter \& Co, Berlin

DOI: $10.1515 / 9783110244892.260$ 


\section{Neuere Literatur zu Humanismus und Gelehrsamkeit im Spanien des 16. Jahrhunderts}

Von Christoph Strosetzki

Der spanische Humanismus, der vor dem Hintergrund des europäischen Phänomens des Humanismus und der Renaissance gesehen werden muß ${ }^{1}$, hat gerade in den letzten Jahrzehnten verstärkt das Interesse der Forschung auf sich gezogen. Die neuere Literatur zu Humanismus und Gelehrsamkeit im Spanien des 16. Jahrhunderts ist so umfangreich und vielfältig, daß hier nicht der Anspruch erhoben werden kann, alle Forschungsbeiträge der letzten zehn Jahre erfaßt zu haben. Der folgende Bericht vermeidet es, die Forschung nur auf einige, von uns als zentral erkannte Probleme zu befragen. Er versucht vielmehr, Intentionen und Anliegen der Detailforschungen besonders zu berücksichtigen. Da es bei dieser Zielsetzung zunächst auf Information ankommt, wird bewußt auf bewertende Kritk weitgehend verzichtet. Es geht uns vielmehr darum die verschiedenen Bereiche der Forschung zum spanischen Humanismus und die Vielfalt der Fragestellungen vorzuführen.

Zur spezifischen Problematik der spanischen Renaissance liegen bereits ältere Forschungsberichte vor. Einen umfassenden Úberblick über die Jahre 1914-1944 bietet Otis H. Green ${ }^{2}$. Er korrigiert das schwer ausrottbare Vorurteil von Spanien als einem Land ohne Renaissance durch die Darstellung der Forschungen von Menéndez Pelayo, Américo Castro, Aubrey F.G. Bell, Marcel Bataillon, Ángel Valbuena Prat und Federico de Onís sowie durch den Verweis auf die Ausbreitung der kastilischen Sprache, den Aufschwung der griechischen und hebräischen Studien bis hin nach Amerika und auf bibliophile, philosophische, reformatorische und mystische Bestrebungen.

Alexander A. Parker will in seinem Bericht von 1968 die Rolle der conversos, d.h. des jüdischen Elements, dessen Bedeutung seit Américo Castro häufig überbetont worden war, relativieren. Dabei bezieht er sich auf Eugenio Asensio, der nachweist, $\mathrm{da} ß$ gerade jene spanischen Charakterzüge, die nach Castro Spanien vom übrigen Europa trennen und der semitischen Tradition zuordnen, auch in Italien vorfindbar

1 Zur Renaissance als europäisches Phänomen vgl. den Bericht von A. Buck, Úberlegungen zum gegenwärtigen Stand der Renaissanceforschung, BHR 43 (1981) S. 7-38; zur literaturgeschichtlichen Information vgl. A. Buck, Einleitung: Renaissance und Barock und Die humanistische Literatur in der Romania, in Neues Handbuch der Literaturwissenschaft, Bd. 9: Renaissance und Barock I, hrsg. A. Buck, Frankfurt/M. 1972, S.1-81.

2 O.H. Green, A Critical Survey of Scholarship in the Field of Spanish Renaissance Literature, in Studies in Philology 44 (1947) S. 228-64. 
sind. Parker weist darauf hin, daß diese Verbundenheit mit der westeuropäischen Tradition im Werk von Green betont und ausführlich dargelegt wird ${ }^{3}$.

In einem neueren, statistisch orientierten Forschungsbericht stellt Theodore S. Beardsley Jr. für die Jahre 1945-75 für je fünf Jahre eine Liste der „Top Twenty“, d.h. der von der Forschung am häufigsten behandelten Schriftsteller, auf und bemerkt, daß sich nur $27 \%$ aller Forschungen mit der Vielzahl der weniger kanonisierten Autoren beschäftigen. In statistischen Listen erfaßt er auch die Ausrichtung der Studien (z.B. auf Gattungen, Themen, Strömungen oder Einflüsse) sowie die Verfasser dieser Untersuchungen, um z.B. herauszufinden, daß „Scholars who reach their productive peak in one decade (usually when they are in their forties) tend to be of significant influence on graduate studies in the next decade (in their fifties)" ${ }^{\text {"4 }}$

Wertvoll für bibliographische Hinweise und zur Einführung in neuere Forschungsperspektiven sind drei kürzlich erschienene spanische Literaturgeschichten. Die philosophisch orientierte Historia crítica del pensamiento español von José Luis Abellán sieht die spanische Renaissance durch die Entdeckung Amerikas und die damit verbundene Erweiterung literarischer und kultureller Horizonte geprägt. Das führt den Autor zur verstärkten Auseinandersetzung mit der geistesgeschichtlich bedeutsamen Verarbeitung der neuen Lage, z.B. durch den Utopiegedanken und den Mythos des buen salvaje ${ }^{5}$. Der 1980 überarbeitete zweite Band der von José María Diez Borque herausgegebenen Literaturgeschichte, der sich mit der Renaissance und dem Barock beschäftigt, besteht aus Originalbeiträgen mit unterschiedlichen methodischen Ansätzen, die nach Jahrhunderten und Gattungen eingeteilt und durch eine kurze kritische Bibliographie ergänzt sind ${ }^{6}$. Der von Francisco López Estrada herausgegebene

3 A.A. Parker, Recent Scholarship in Spanish Literature, in Renaissance Quarterly 21 (1968) S.118-24; vgl. O.H. Green, Spain and the Western Tradition: the Castilian Mind in Literature from «El Cid» to Calderón, 4 Bde., Madison, Wisconsin 1963-66; zu der Kontroverse vgl. auch E. Asensio, La España imaginada de Américo Castro, Barcelona 1976; gegen Green und zugunsten von Castro polemisiert F. Márquez Villanueva, Sobre la occidentalidad cultural de España, in: F.M.V., Relecciones de literatura medieval, Sevilla 1977, S. 135-68 (hier S. 139).

4 T.S. Beardsley, Jr., Spanish Literature, in The Present State of Scholarship in SixteenthCentury Literature, hrsg. W. M. Jones, Columbia-London 1978, S. 71-110. Der von Beardsley beklagte Mangel an verfügbaren Neuausgaben besteht nach wie vor. Vgl. aber A.M. Arancón (Hrsg.), Antología de humanistas españoles, Madrid 1980; zu weiteren Neuausgaben vgl. die 3. verbesserte Auflage von J. Simón Díaz, Manual de bibliografía de la literatura española (Biblioteca Románica Hispánica. Manuales 47), Madrid 1980.

5 J.L. Abellán, Historia crítica del pensamiento español, Bd. 2: La edad de oro, Madrid 1979; zu Amerika als Kapitel der „Historia de las ideas“" vgl. J.L. Abellán, La idea de América: origen y evolución, Madrid 1972; zum utopischen Verständnis Amerikas: J.A. Maravall, Utopía y primitivismo en el pensamiento de Las Casas, ROcc. 141 (1974) S. 311-88; zur Utopie als rückwärtsgerichtete Sehnsucht nach der eigenen verlorengegangenen großen Zeit der Reconquista: S. Gilman, The Problem of Spanish Renaissance, in Studies in the Literature of Spain, $16^{\text {th }}$ and $17^{\text {th }}$ Centuries, hrsg. M.J. Ruggerio, New York 1977, S. 37-57.

6 J.M. Diez Borque (Hrsg.), Historia de la literatura española, Bd. 2: Renacimiento y barroco, Madrid 1980, mit dem einführenden Artikel von J. B. Avalle-Arce, Características generales del renacimiento literario. 
zweite Band der von Francisco Rico betreuten Literaturgeschichte vereinigt zwei Vorzüge in sich: er enthält eine chronologisch und thematisch geordnete Auswahl von Texten aus der internationalen Forschung sowie Einführungen in die Literatur und die Forschungsergebnisse zu einzelnen Jahrhunderten, Generationen, literarischen Strömungen und besonders bedeutenden Autoren?

\section{Vorstufen im 15. Jahrhundert}

Den Beginn der spanischen Renaissance verfolgen Karl Kohut und Ottavio Di Camillo ins 15. Jahrhundert zurück. Kohut betrachtet die Stellung der Literatur als poesia, arte oder ciencia ohne Gattungsunterschiede innerhalb der artes liberales, des scholastischen und des humanistischen Denkens. Während in der scholastischen Wissenshierarchie die Literatur, der Lüge verdächtigt, die unterste Stufe einnehme, verselbständige sie sich in den studia humanitatis, gestützt durch die artes de trobar; sie werde unabhängig von Grammatik und Rhetorik und erhalte sogar das Verdienst, die übrigen Wissensgebiete zu tradieren. Im Universitätsunterricht löse diese Konzeption erst Ende des Jahrhunderts das scholastische Curriculum ab und erleide Anfang des 16. Jahrhunderts einen erneuten Rückschlag8. Wie sehr im 15. Jahrhundert die Literatur vom Standort der Theologie aus beurteilt wird, zeigt Kohut im Hinblick auf Alonso de Cartagena und Alonso de $\mathrm{Madrigal}^{9}$. Cartagenas Literaturbegriff sei in den Prologen und Kommentaren seiner Úbersetzungen Ciceros und Senecas enthalten. Madrigal beurteile die Dichtung in seinen Bibelkommentaren negativ, in den Kommentaren zu Eusebius positiv. Er kenne antike und italienische Literatur besser als Cartagena, sei aber nicht mehr wie jener imstande, den Konflikt zwischen geistlicher und weltlicher Wissenschaft auszugleichen. Während Cartagena an der Rhetorik und Moralphilosophie der römischen Antike interessiert sei, gelte Madrigals Interesse der Mythologie, die er als historische Quelle und poetische Form betrachte. Trotzdem hielten beide an einer literaturfeindlichen Vorrangstellung der Theologie fest.

Wie Kohut räumt Di Camillo Cartagena eine besondere Stellung unter den frühen Humanisten ein. Im Prolog zu Cartagenas Übersetzung von Ciceros De inventione zeige sich „el primer documento del humanismo español“"10. Humanismus wird hier mit Kristeller als spezifische Phase in der Entwicklung der abendländischen rhetorischen Tradition verstanden. Einen ersten Beginn der Renaissance sieht Di Camillo in der Übernahme italienischer Ideen durch spanische Gelehrte in Avignon, die nach der Wahl des aragonesischen Gegenpapstes Pedro de Luna, bekannt als

7 F. Rico (Hrsg.), Historia y crítica de la literatura española, Bd. 2; F. López Estrada (Hrsg.), Siglos de Oro: Renacimiento, Barcelona 1980; vgl. darin bes. F. Rico, Temas y problemas del renacimiento español, und A. Castro Díaz, Prosa y pensamiento.

$8 \mathrm{~K}$. Kohut, La posición de la literatura en los sistemas científicos del siglo $X V$, in Iberoromania 7 (1978) S. 67-87.

9 K. Kohut, Der Beitrag der Theologie zum Literaturbegriff in der Zeit Juans II. von Kastilien, RF 89 (1977) S. 183-226.

10 O. Di Camillo, El humanismo castellano del siglo XV, Valencia 1976, S. 66. 
Benedikt XIII., im Jahr 1394 möglich geworden ist. Im Gegensatz zu Kohut will er Madrigal aufgrund seines zyklischen Geschichtsbildes nicht als Humanisten gelten lassen: ,su visión del mundo era completamente medieval"“11. Cartagenas Streit mit Leonardo Bruni zeige, daß er mit der antiken Tradition kritisch und distanziert umgehe; als Spanier und konvertierter Jude betone er ständig die christlich-jüdische Tradition, und im Interesse der kastilischen Monarchie sei er nicht darauf bedacht, die kulturelle Vorherrschaft Roms wiederherzustellen. Folglich sehe er auch die gotischen Invasionen nicht als Beginn einer dunklen Epoche, sondern als Anfang der Entwicklung des spanischen Staates. So sind es nach Di Camillo eher politische als die von Kohut genannten theologischen Motive, die für das trotz allem kritische Verhältnis Cartagenas zur Antike verantwortlich sind. Di Camillos Analyse zeigt die Notwendigkeit der Beschäftigung mit dem 15. Jahrhundert zum besseren Verständnis der humanistischen Literatur und der Gelehrsamkeit im Spanien des 16. Jahrhunderts $^{12}$. So behalten wir uns vor, auch in späteren Abschnitten auf die Vorstufen im 15. Jahrhundert zurückzukommen.

\section{Antiker Einflu $\beta$}

Wie die Antike in den romanischen Literaturen der Renaissance rezipiert worden ist, hat August Buck ausführlich für Italien und Frankreich dargestellt ${ }^{13}$. Er fragt nach den Gegenständen der Überlieferung, ihrer Bearbeitung in Philosophie, Geschichtsschreibung und Dichtung, der Querelle des Anciens et des Modernes und nach dem erstarkten epochalen Selbstbewußtsein der Modernen.

Die Berufung der spanischen Humanisten auf die eigene Vernunft und den eigenen kritischen Geist bei aller Verehrung für die antiken Autoren veranlaßte die Theologen, auch im religiösen Bereich um das Prinzip der Autorität zu fürchten. So entsteht nach Kohut in Spanien die paradoxe Situation, ,daß die Theologen die Autorität der antiken (heidnischen!) Autoren gegen die Humanisten verteidigen: die Humanisten werden zu Verteidigern der ,Modernen', die Theologen zu Verteidigern der ,Alten“" 14 .

Die Definition des Selbstverständnisses im Hinblick auf die antike Vergangenheit führt zwangsläufig zu einer Auseinandersetzung mit der Idee des Fortschritts ${ }^{15}$.

11 Di Camillo, S.115.

12 Vgl. auch H. Flasche, Geschichte der spanischen Literatur, 1. Band: Von den Anfängen bis zum Ausgang des 15. Jahrhunderts, Bern-München 1977 (z.B. S. 311 zu Iñigo López de Mendoza).

13 A. Buck, Die humanistische Tradition in der Romania, Bad Homburg-Berlin-Zürich 1968; A. Buck, Die Rezeption der Antike in den romanischen Literaturen der Renaissance, Berlin 1976.

14 K. Kohut, "Ingeniosa comparación entre lo antiguo y lo presente». Aufnahme und Kritik der antiken Tradition im spanischen Humanismus, in Renatae Litterae. Studien zum Nachleben der Antike und zur europäischen Renaissance. August Buck zum 60. Geburtstag, hrsg. K. Heitmann/E. Schroeder, Frankfurt/M. 1973, S. 217-243 (Zit. S. 238):

15 Vgl. J. A. Maravall/M. Batllori, Los factores de la idea de progreso en el renacimiento espanol, Madrid 1963 [Reden vor der Real Academia de la Historia]; vgl. auch H. R. Jauss, 
José Antonio Maravall sucht die Ursprünge der Fortschrittsidee des 18. Jahrhunderts in den Auseinandersetzungen zwischen antiqui und moderni der vorausgehenden Jahrhunderte. Nach einer Phänomenologie der Wertschätzung des Neuen und der Einordnung der Fortschrittsidee in unterschiedliche kulturelle Strömungen des 16. Jahrhunderts behandelt Maravall in einem weitgefächerten Panorama die geistesgeschichtlichen Faktoren des Fortschrittsbewußtseins (z.B. Kontinuitätsgefühl, Erwachen des historischen Bewußtseins, Vernunftautonomie), die Rolle der Entdeckung Amerikas und daneben die Manifestationen dieses Bewußtseins in literarischen, politischen, wirtschaftlichen und militärischen Traktaten sowie in der modernen Technik $^{16}$.

Die Präsenz der Antike wurde auch in Studien zu einzelnen Autoren nachgewiesen. So hat Karl Alfred Blüher die Seneca-Rezeption in Spanien verfolgt. Dabei hat er eine Unterbrechung vom 7. bis zum 13. Jahrhundert festgestellt und gezeigt, wie die erste ideelle Aneignung bei dem Marqués de Santillana in enger Verflechtung mit der gesamteuropäischen Entwicklung im 15. Jahrhundert gestanden hat. In der Renaissance sei Erasmus' kritische, echte von unechten Schriften trennende Seneca-Edition maßgeblich gewesen. Sie habe auch die Basis für Vives' Auseinandersetzung mit der aristotelisch-scholastischen Ethik gebildet ${ }^{17}$.

José López Rueda betrachtet den spanischen Hellenismus des 16. Jahrhunderts als Kapitel der Geschichte der klassischen Philologie ${ }^{18}$. Jenseits jeder einseitig verklärenden oder abschätzigen Beurteilung des spanischen Beitrags zur Graezistik im 16. Jahrhundert wird in seiner großangelegten Studie die Geschichte der Lehrstühle des Faches an den wichtigsten Universitäten analysiert. Der Autor beschreibt und bewertet die Grammatiken des Griechischen, die im Spanien des 16. Jahrhunderts erschienen sind, informiert über die Theorie des Griechischunterrichts nach den Vorworten griechischer Grammatiken und Erziehungstraktate, wie z. B. Vives' De tradendis disciplinis, er trägt Dokumente zur Praxis dieses Unterrichts aus zahlreichen Archiven zusammen und bewertet spanische Editionen griechischer Texte aus dem 16. Jahrhundert sowie Ưbersetzungen aus dem Griechischen. Ausführlich hebt er den Anstoß hervor, den Ignatius' Werk und die Jesuiten der zweiten Jahrhunderthälfte für die Verbreitung des Griechischunterrichts gegeben haben. Auskünfte zur Editionstechnik entnimmt er bei der geringen Zahl griechischer Editionen den lateinischen Ausgaben bzw. den Akten der häufig mit ihnen verbundenen Inquisitionsprozesse.

Antiqui/moderni (Querelle des Anciens et des Modernes), in: J. Ritter (Hrsg.), Historisches Wörterbuch der Philosophie, Bd. 1, 1971, Sp. 409-14.

16 J.A. Maravall, Antiguos y modernos. La idea de progreso en el desarrollo de una sociedad, Madrid 1966; Maravalls eigene Zusammenfassung dieser Fortschrittsidee: Un humanisme tourné vers le futur: littérature historique et vision de l'histoire en Espagne au XVI siècle, in: A. Redondo (Hrsg.), L'humanisme dans les lettres espagnoles, Paris 1979, S. 337 bis 48 [XIX ${ }^{\mathrm{e}}$ Colloque international d'études humanistes, Tours 1976].

17 K.A. Blüher, Seneca in Spanien. Untersuchungen zur Geschichte der Seneca-Rezeption in Spanien vom 13. bis 17. Jahrhundert, München 1969.

18 J. López Rueda, Helenistas españoles del siglo XVI, Madrid 1973. 
Die soziologisch orientierte Studie von Luis Gil Fernández über den spanischen Humanismus zeigt, daß die Beschäftigung mit der Antike in Spanien trotz großer Einzelleistungen nicht als breite kulturelle Kraft zu bewerten ist; es fehlte die Wirkung auf weite, des Lateinischen unkundige Kreise, die theologische und juristische Fragen höher einschätzten als die der litterarum amoenitates ${ }^{19}$.

\section{Wirkung und Verbreitung des Humanismus}

In vielen Bereichen ist humanistisches Denken wirksam geworden. Einige seien genannt: In der Logik hebt Cardillo de Villalpando in Alcalá die Unterscheidung zwischen Dialektik und Logik im Sinne Agricolas auf, indem er die Rhetorik in der Dialektik fundiert und die aristotelische Logik in ihrer ursprünglichen, von späteren Hinzufügungen unverfälschten Reinheit wiederherstellt ${ }^{20}$. In der Theologie ergeben sich zur Zeit Cisneros' Beeinflussungen und U'bereinstimmungen mit dem Humanismus, wie Melquiades Andrés in seinem Standardwerk zu theologischen Strömungen, Ereignissen, Institutionen und Personen in ihrem kulturellen, sozialen und politischen Umfeld hervorhebt. Er nennt dazu vierzehn Punkte, u. a. die Fortschrittsidee, das Sprachenstudium als Vorbereitung für das Textstudium, Betonung von Menschenwürde und Menschenrechten, Suche nach Selbsterkenntnis und Wissen, inneres Christentum, Glaube an die Perfektibilität des Menschen:

Esta conjunción de humanismo y teología en España constituye el núcleo más importante de la reforma teológica en España y se realiza sobre todo en las facultades de teo$\operatorname{logí}{ }^{21}$.

$\mathrm{Daß}$ auch ein Vertreter der Scholastik wie Melchior Cano in Los lugares teológicos (1563) trotz grundsätzlicher Opposition zum Humanismus humanistische Ansichten vertreten kann, zeigt sich nach Joseph Pérez darin, daß er scholastische Sophistereien als steril und lächerlich kritisiert, daß er Aristoteles zwar verehrt, ihn aber nicht kritiklos als Autorität übernimmt, und daß er schließlich den Mangel an stilistischer Sorgfalt in theologischen Schriften z.B. auch des Thomas von Aquin beklagt $^{22}$.

19 L.G. Fernandez, El humanismo español del siglo XVI, in Estudios Clásicos 11 (Madrid 1967) S. 209-97 (hier S. 217).

20 Vgl. V. Muñoz Delgado, Cardillo de Villalpando y la lógica renacentista en Alcalá, in Estudios 26 (Madrid 1971) S. 511-55. Zur humanistischen Reaktion z.B. eines Vives gegen die von spanischen Professoren der Pariser Universität vertretene „,barbarische Dialektik“ vgl. C.G. Noreña, Spanish Logicians of Montaigu College, in: C.G.N., Studies in Spanish Renaissance Thought, (Archives Internationales d'Histoire des Idées 82), Den Haag 1975.

21 M. Andrés, La teología española en el siglo XVI, 2 Bde., Madrid 1976; Bd. 2, S. 61.

22 J. Pérez, Humanismo y escolástica, CuH 334 (1978) S. 28-39. Zu den loci theologici, die Cano aus der mittelalterlichen und antiken Topiklehre aufgreift und zu einer philologischen Hilfswissenschaft umarbeitet, die Fundstellen für Glaubenswahrheiten angibt, vgl. K. Hölz, Im Banne des Dogmas. Fray Luis de León und der spanische Humanismus (im Druck). 
Anläßlich der Herausgabe des Espejo de príncipes y cavalleros von Diego Ortúñez de Calahorra durch Daniel Eisenberg fragt Kohut nach dem humanistischen Charakter dieses Ritterromans. Eisenberg sehe in dem Roman den Versuch der Verschmelzung von Humanismus und Ritterroman. Dem schließt sich Kohut im wesentlichen an, wenngleich er auch die Möglichkeit zu bedenken gibt, daß es sich hier um einen rein äußerlichen Humanismus handelt, für den antike Mythen und didaktische Zielsetzung nur Zugeständnis an den Zeitgeschmack und Schutz vor kirchlicher und humanistischer Kritik sind. Der Mangel an Ironie, die sich von einem anachronistischen Weltbild zu distanzieren hätte, verweise allerdings das Werk in den Bereich ,trivialer" Literatur ${ }^{23}$.

Die Verbreitung des Humanismus außerhalb von Kastilien in Katalonien und Aragon belegt Miquel Batllori, indem er auf die Bedeutung der Grant crónica de Espanya und der Crónica de los conquiridores von Don Juan Fernández de Heredia für die Kontakte mit der byzantinischen Kulturwelt im 14. Jahrhundert ebenso hinweist wie auf die Entsendung des Crisoloras 1407/10 unter König Martin I. nach Barcelona und an den Hof Alfons' des Großmütigen in Neapel. Doch weder diese Kontakte noch die zahlreichen von Batllori genannten Übersetzungen griechisch-lateinischer Autoren könnten das Entstehen der humanistischen Kultur erklären, gäbe es nicht den Einfluß der italienischen Humanisten und Trecentisten. Ausführlicher stellt er Bernat Metge aus Barcelona (1340/46-1413) als ersten Humanisten der Iberischen Halbinsel vor. Für das 16. Jahrhundert nennt er besonders Vives und Miquel Mai. Erasmus sei in den ersten Jahrzehnten des 16. Jahrhunderts im Fürstentum Katalonien weniger verbreitet als in Valencia, deswegen aber nicht weniger bewundert ${ }^{24}$.

\section{Erasmus}

Auf die Prägung des spanischen Humanismus durch die Gestalt des Erasmus hatte schon Menéndez y Pelayo hingewiesen. Die detaillierte Analyse des spanischen Eras-

$23 \mathrm{~K}$. Kohut, Humanismo y novelas de caballerias. Algunas razones para leer una despreciada novela de caballerías, in Iberoromania 10 (1979) S. 63-76; vgl. Diego Ortúñez de Calahorra, Espejo de príncipes y cavalleros, hrsg. D. Eisenberg (CC 193-98), 6 Bde., Madrid 1975. Zu anderen Gattungen, z. B. zur Epigrammtheorie, vgl. J. Nowicki, Die Epigrammtheorie in Spanien vom 16. bis 18. Jahrhundert. Eine Vorarbeit zur Geschichte der Epigrammatik (Untersuchungen zur Sprach- und Literaturgeschichte der Romanischen Völker 7), Wiesbaden 1974; zur apophtegmatischen Literatur vgl. A. Blecua, La littérature apophtegmatique en Espagne, in L'humanisme dans les lettres espagnoles, S. 119-32.

24 M. Batllori, Der katalonisch-aragonische Humanismus vom 14. bis zum 16. Jahrhundert (Vorträge der Aeneas-Silvius-Stiftung an der Universität Basel 12), Basel-Stuttgart 1977; zu den wechselseitigen Beziehungen zwischen Italien und Spanien vgl. E. Asensio, Damasio de Frías y su «Dórida », diálogo de amor. El italianismo en Valladolid, NRFH 24 (1975) S. 219-34; A. Rumeu de Armas, Alfonso de Ulloa, introductor de la cultura española en Italia, Madrid 1973; P. Lopez, Il movimento valdesiano a Napoli. Mario Galeota e le sue vicende col Sant'Uffizio, Napoli 1976; zu Verbindungen von Spanien nach England und Frankreich vgl. die kritische Bibliographie von H.U. Stubbings, Renaissance Spain in its Literary Relations with England and France, Nashville 1969. 
mismus ist Marcel Bataillon zu verdanken, seiner 1937 in Frankreich erschienenen und noch heute grundlegenden Arbeit Erasme et l'Espagne, korrigiert und erweitert in zwei spanischen Ausgaben 1950 und 1966, neugedruckt 1979, sowie seinen zahlreichen Reden und Aufsätzen, von denen einige 1977 in einem Sammelband erschienen $^{25}$. Darin wertet er z.B. entgegen seinen ursprünglichen Ansichten die Bedeutung des Erasmischen Encomium moriae auf und faßt den Erasmismus wie folgt zusammen:

España, predispuesta por corrientes iluministas a comprender el espiritualismo del Enchiridion, había sido un país singularmente acogedor, bajo Carlos $\mathrm{V}$, al evangelismo erasmiano y a su alegato en favor del culto en espíritu; que en España [...] una élite eclesiástica y monástica no había temido hacerse eco del «monachatus non est pietas » [...] y que este erasmismo había calado tan profundamente que existen huellas suyas hasta en la época de Felipe II, en maestros de espiritualidad de la reforma católica (S. 327).

Der Ausdruck „Erasmianus“ oder „Erasmicus“ ist keine Schöpfung von Bataillon: er wird bereits im 16. Jahrhundert gebraucht. Wie sich das Phänomen des Erasmismus in jedem Land anders darstellte, könnte nach Bataillon eine ,,geografía del erasmismo" zeigen. Dabei sei zu beachten, daß die Berufung auf Erasmus' Schriften nicht selten der unverdächtigen Verbreitung heterodoxen Gedankengutes diente. Denn der orthodoxe Charakter von Erasmus' Lehren war von höchster Stelle anerkannt. So kann Juan de Valdés sich vielleicht nur auf Erasmus berufen haben, um von seinem Werk den Verdacht des Illuminatentums abzuwenden. Er war nämlich stark durch den von der Inquisition verfolgten Alcaraz beeinflußt ${ }^{26}$.

Zum Erasmismus gehört für Bataillon auch die primär pastorale Auffassung des Priesteramts, verbunden mit der Missionsidee und der Forderung, auch weitentfernte, neuentdeckte Völker zu missionieren. Die Frage, warum der religiöse Einfluß des Erasmus nach 1560 mit Festigung der protestantischen Konfessionen und Indizierung von Erasmus' Werken weitgehend schwindet, um im 17. Jahrhundert wieder an Bedeutung zu gewinnen, läßt Bataillon offen. Erasmus' Präsenz in Cer-

25 M. Bataillon, Erasmo y España. Estudios sobre la historia espiritual del siglo XVI, MéxicoMadrid-Buenos Aires 1979; M. Bataillon, Erasmo y el erasmismo, pref. F. Rico, Barcelona 1977.

26 M. Bataillon, Erasmo y el erasmismo, S.148, 153f. Die Frage, ob Alcaraz selbst unter lutheranischem Einfluß stand, beantwortet Redondo positiv: A. Redondo, Luther et l'Espagne de 1520 à 1536, in Mélanges de la casa de Vélasquez, Bd. 1, Paris 1965, S. 109-65; Nieto dagegen hält das durch Redondos Argumente nicht für bewiesen: Alcaraz sei nicht als Lutheraner, sondern bestenfalls als den comuneros nahestehender alumbrado von der Inquisition angeklagt. Mit Redondo behauptet er aber, Alcaraz habe sich als Erasmianer ausgegeben, ohne Erasmus zu kennen, nur um von der Inquisition ein geringeres Strafmaß zu erlangen. Er fordert die methodologische Trennung von Sein und Schein und eine Neuformulierung der alten Fragestellung: „Erasmus and Spain or Erasmus' masks in Spain?“ sowie die Annahme eines innerspanischen Valdesianismus als zusätzliche Strömung: J.C. Nieto, Luther's Ghost and Erasmus' Masks in Spain, BHR 39 (1977) S. 33-49. Neuerscheinungen zu mystischen und protestantischen Strömungen bleiben in diesem Bericht außer Betracht. 
vantes' Werk, die Américo Castro betont hatte, wie seinen literarischen Einfluß im post-tridentinischen Spanien bestätigt er. Sogar die Compañía de Jesús suche ihr Selbstverständnis in Auseinandersetzung mit Erasmus und ihren Platz zwischen traditionellem Mönchtum und Erasmischem Humanismus und definiere so die innerkatholische Reform des 16. Jahrhundert ${ }^{27}$.

Das Fortleben des Erasmismus bis auf den heutigen Tag, etwa in der europäischen Idee, thematisiert José Luis Abellán. Er versteht den Erasmismus als ,estado de espíritu“, will die Ergebnisse von Bataillon, Montesinos, Alonso und Asensio zusammenfassen und einem größeren Publikum zugänglich machen. Er ergänzt Bataillon, indem er Vives stärker in den Vordergund stellt, den Erasmismus als greifbaren Beweis einer spezifisch spanischen Renaissancephilosophie versteht und als zentrale These formuliert, „,que el núcleo doctrinal del erasmismo español giraba en torno a la interpretación horizontal de la metáfora del «cuerpo místico » de Cristo; horizontalidad derivada a su vez del origen social converso de dicha metáfora" 28 . Allerdings erlaube dieser „mito de Cristo“ keine Unterscheidung zwischen orthodoxen Autoren wie Fray Luis de León, Fray Luis de Granada, Beato Juan de Ávila und Alejo Venegas und heterodoxen wie z. B. Miguel Servet.

Seit dem Erscheinen von Erasmus' Ciceronianus 1528 in Basel befehden sich die zuvor friedlich koexistierenden Gruppen der Ciceronianer und der Erasmianer. Dabei erscheint der Ciceronianismus vielen Spaniern mit einem ästhetisierenden italienischen Nationalismus verbunden. Eugenio Asensio zentriert die Auseinandersetzung in zwei Punkten: der Rezeption des Ciceronianus durch die Humanisten Juan de Maldonado aus Burgos und Juan Luis Vives aus Flandern und dem Opusculum von Lorenzo Palmireno über die Nachahmung von Cicero, das einen Einblick in den Streit zwischen Erasmianern und Ciceronianern in der gegen 1560 italienischen Ideen aufgeschlossenen Stadt Valencia erlaubt ${ }^{29}$. Ein anderes Werk des Erasmus über die Sprache, La lengua, wurde 1528 von Bernardo Pérez de Chinchón ins Spanische übersetzt. Es liegt jetzt in einer von Dorothy S. Severin besorgten Neuausgabe mit ausführlicher Einführung vor ${ }^{30}$.

Aufschlußreich für die Haltung spanischer Humanisten zu Erasmus im gleichen Jahr 1528, d.h. in der Zeit der von Mönchen spanischer Bettelorden geführten Kampagne zum Zweck der kirchlichen Verurteilung einiger als häretisch angesehener Werke des Erasmus, ist der 7. Band der Neuausgabe der Briefe von und an Erasmus in der französischen Übersetzung ${ }^{31}$. Ein anderes Beispiel für den Erasmismus ist nach Erich Loos der Diálogo de las cosas ocurridas en Roma von Alfonso de Valdés, der die Rolle des Kaisers bei der Plünderung Roms rechtfertigt, die erasmische Kritik

27 M. Bataillon, Erasmo y el erasmismo, S. 348f, $203 \mathrm{f}$.

28 J.L. Abellán, El erasmismo español. Una historia de la otra Expaña, Madrid 1976, S. 13.

29 E. Asensio, Ciceronianos contra erasmistas en España. Dos Momentos (1528-1560), RLC 52 (1978) S. 135-54.

30 D.S. Severin (Hrsg.) La lengua de Erasmo nuevamente romançada por muy elegante estilo. Traducción española del siglo XVI por Bernardo Pérez de Chinchón, Madrid 1975.

31 La correspondance d'Erasme, traduite et annotée d'après le texte latin de l'Opus Epistolarum de P.S. Allen, Bd. 7 (1527-28), Bruxelles 1978. 
an kirchlichen Mißständen übernimmt und im Gegensatz zu Castiglione ,zum militanten Verfechter einer radikalen Utopie“" wird ${ }^{32}$.

\section{Buchdruck, Zensur, Inquisition}

Zentral für die Ausbildung des Humanismus ist die Entstehung des Buchdrucks ${ }^{33}$. Für einen Ưberblick über Bekanntheitsgrad und Beliebtheit antiker Werke sind Darstellungen der Verfügbarkeit und Nachfrage von hohem Wert. Theodore S. Beardsley Jr. zeichnet nach, welche antiken Autoren in den unterschiedlichen Städten Spaniens im Zeitraum von 1482-1599 gedruckt wurden, wobei er auch spanische, außerhalb der Iberischen Halbinsel gedruckte UUbersetzungen berücksichtigt ${ }^{34}$. Wie allerdings Analphabetismus, hoher Bücherpreis und mangelndes Interesse an der Lektüre das Lesepublikum der Unterhaltungsliteratur auf Gruppen der hidalgos und caballeros, der letrados und Universitätslehrer, einen Teil des Klerus und gebildete Diener großer Familien einschränkte - noch geringer wird das Publikum für humanistische Schriften gewesen sein -, stellt Maxime Chevalier in seiner Bestandsaufnahme der damaligen privaten Bibliotheken fest ${ }^{35}$.

Zum fünfhundertsten Jahrestag der Einführung des Buchdrucks in Spanien erinnert Carlos Romero de Lecea an die Rolle des Spaniers Juan de Torquemada als Protektor der Anfänge des Buchdrucks im italienischen Subiaco und in Rom. Gleichzeitig zeigt er die Beziehungen zwischen Segovia und Rom in der zweiten Hälfte des 15. Jahrhunderts und die Anfänge der Druckerei in Segovia $1472^{36}$.

Schon bald sah sich die Verbreitung gedruckter Erzeugnisse Einschränkungen ausgesetzt. Luis Gil Fernández will die Wissensverbreitung durch Buch und Unterricht vor dem Hintergrund eines wirtschaftliche Konsolidation suchenden Spaniens verstanden wissen, in dem, ,no es la nobleza la que asimila los ideales de la burguesía, sino la burguesía la que asume la tabla de valores de la nobleza“"37.

32 E. Loos, Der Briefwechsel zwischen Alfonso de Valdés und Baldassare Castiglione (1528). Spanischer Erasmismus und italienische Vor-Gegenreformation?, in Spanische Literatur im Goldenen Zeitalter. Fritz Schalk zum 70. Geburtstag, hrsg. H. Baader/E. Loos, Frankfurt/M. 1973, S. 269-88 (Zit. S. 287).

33 Vgl. dazu allgemein: F. Krafft/D. Wuttke (Hrsg.), Das Verhältnis der Humanisten zum Buch (Kommission für Humanismusforschung. Mitteilung 4), Boppard 1977.

34 T.S. Beardsley, Jr., Spanish Printers and the Classics: 1482-1599, HR 47 (1979) S. 25-35; vgl. auch T.S.B., Jr., Hispano-Classical Translations Printed between 1482 and 1699, Pittsburgh 1970.

35 M. Chevalier, Lectura y lectores en la España del siglo XVI y XVII, Madrid 1976.

36 C. R. de Lecea, El V. centenario de la introducción de la imprenta en España, Segovia 1472. Antecedentes de la imprenta y circunstancias que favorecieron su introducción en España, Madrid 1972; vgl. auch F. J. Norton, A Descriptive Catalogue of Printing in Spain and Portugal (1501-1520), Cambridge 1978.

37 L.G. Fernández, Apuntamientos para un análisis sociológico del humanismo español, in Estudios Clásicos 83 (1979) S.143-71 (Zit. S. 151). 
War noch 1480 das freie Zirkulieren von Büchern durch Gesetz gestattet, so wurde 1502 jedes ,,apocripha y supersticiosa“ erscheinende bzw. „,cosas vanas y sin provecho" enthaltende Werk nach Prüfung vernichtet. 1531 verbot die Inquisition, fiktionale Texte wie den Amadís nach Amerika auszuführen, bis schließlich 1572 zur besseren Kontrolle Plantin ein Monopol zum Druck und der Buchhandlung Jerónimos de El Escorial ein Monopol zum Verkauf religiöser Literatur verliehen wurden. Den humanistischen Grammatik- und Lateinlehrern warf man Eigendünkel und Heterodoxie vor. Antiken Autoren wurde der Erziehungswert abgesprochen. Der Humanist selbst sei als „,ser híbrido de grammático y hereje“ und gefährlicher „,crítico social y activista subversivo" angegriffen worden. Ihm trete die jesuitische Bildung entgegen mit einem „nuevo tipo de humanista «sine aculeo», domesticado, sumiso, amable con los discípulos, respetuoso con las jerarquías y consciente de la humildad de su función" ${ }^{\text {38 }}$.

Auf die schnellere Verbreitung von religions- und staatsfeindlichen Ideen durch das Buch mußten also Zensur und Inquisition mit entsprechend starker Kontrolle reagieren. Aufschlußreich in diesem Zusammenhang ist der von Luis Sala-Molins edierte Manuel des inquisiteurs. Seine Grundlage ist das von dem Katalanen Nicolau Eymerich 1376 verfaßte Directorium inquisitorum, in dem zahlreiche biblische, juristische und kirchliche Texte für die praktische Orientierung des Inquisitors zusammengefaßt sind. Es wurde 1578 von dem Spanier Francisco Peña neubearbeitet und den veränderten Verhältnissen angepaßt ${ }^{39}$. Als Standardwerk des Inquisitors gibt es Auskunft über den Prozeßverlauf, die verschiedenen Typen von Häresie und ihre Anzeichen, über Gestalt, Alter und Legitimation des Inquisitors, sowie mögliche Strafen.

\section{Staat, Gesellschaft, «Comunidades»}

Einige historische Arbeiten seien genannt, soweit sie im Zusammenhang mit der gesellschaftlichen Eingebundenheit des spanischen Humanismus oder seinen Folgen für das politische Denken von Interesse sind. Manuel Fernández Álvarez weist auf den Kontrast zwischen Stadt und Land sowie auf die Verflechtung der spanischen Renaissance in überkommene Lebensformen und Standesstrukturen hin ${ }^{40}$.

Welche „mentalidad social“" im spanischen Staat vom 15. bis zum 17. Jahrhundert zur Ausprägung kam, fragt José Antonio Maravall ${ }^{41}$. Mit Dilthey und Burckhardt nimmt er einen Einfluß der Staatsform auf das individuelle Denken an. Die Staatsform ihrerseits sei im 16. Jahrhundert möglich geworden:

38 L.G. Fernández, Apuntamientos, S. 169.

39 N. Eymerich/F. Peña, Le manuel des inquisiteurs, hrsg. L. Sala-Molins (Le Savoir Historique 8), Paris-Den Haag 1973.

40 M. Fernández Álvarez, La sociedad española del Renacimiento, Salamanca 1970; einführenden Charakter hat: J. Pérez, L'Espagne du XVI siècle, Paris 1973.

41 J.A. Maravall, Estado moderno y mentalidad social (siglos XV a XVII), 2 Bde., Madrid 1972; Bd.1, S. 14. 
[...] porque ha operado con una técnica cuantificadora y se ha visto animado por un espíritu de lucro, porque ha podido disponer de unos ejércitos disciplinados, de acción calculada, y ha tenido a su servicio unos hombres dotados de una cultura minoritaria y especializada que podían encargarse de las funciones burocráticas (Bd.1, S.14).

Maravall kann es gerade in Spanien nicht um das Bürgertum als gesellschaftliche Klasse gehen, sondern um einen ,espíritu burgués“, der das Verhalten bis in den kulturellen Bereich hinein beeinflußt. So stellt er ein ,,esquema aretológico del burgués“ auf, bezieht bürgerliche Beschäftigung mit Kultur auf soziale Aufstiegswünsche des Bürgertums; z.B. dann, wenn reiche Bürger ihre Söhne auf die prestigebeladenen humanistischen Schulen schickten, beginne der „humanismo mercantil“" wie es denn auch nach Maravall die „,misión principal“ des modernen Staates ist, „,de fomentar y favorecer la vida mercantil “42.

In einem Werk über das politische Denken der Renaissance in Spanien stellt J. A. Fernández-Santamaría die Behauptung auf, daß im modernen Denken ,state and war go irrevocably together" ${ }^{43}$. Die Schwierigkeiten, die unter dieser Voraussetzung für eine christliche Staatskonzeption erwachsen, belegt er in seinem Buch, das vor dem Hintergrund der Entdeckung der Neuen Welt das humanistische Denken von Francisco de Vitoria und dem von Las Casas' Anklagen rehabilitierten Sepúlveda zum zeitgenössischen europäischen Denken in Beziehung setzt. Außerdem stellt er Alonso de Castrillo mit seinen imperialen Vorstellungen Alfonso de Valdés und Juan Luis Vives gegenüber und kennzeichnet den Gegensatz zwischen erasmischem Pazifismus und der neuscholastischen Lehre des gerechten Krieges. Die Analyse von Antonio de Guevaras und Fadrique Furió Ceriols Ratschlägen zur Erziehung des Staatsmanns stellt den Bezug zum politisch handelnden Individuum her.

Welche Position einzelne gesellschaftliche Gruppen einnahmen, welche sozialen Konflikte bestanden, äußert sich im revolutionären Aufstand der Comunidades von Kastilien (1520/21), wie Joseph Pérez nachgewiesen hat ${ }^{44}$. Das sich benachteiligt

42 Maravall, Estado, Bd. 2, S. 153, 161, 192. Die Entwicklung der Économie, savoir sans nom de l'Espagne classique von 1500 bis 1650 demonstriert nach J. Vilar und A. Milhou den Konflikt zwischen Staatsdenken und egalitären Bestrebungen besonders in bezug auf die Kaufleute; in Les mentalités dans la Péninsule Ibérique et en Amérique Latine aux $X V I^{e}$ et XVII ${ }^{e}$ siècles. Histoire et problématique, Publications de l'Université de Tours 1978 [13. Kongre $B$ der Société des hispanistes français de l'enseignement supérieur, Tours 1977].

43 J.A. Fernández-Santamaría, The State, War and Peace. Spanish Political Thought in the Renaissance, 1516-1559, Cambridge 1977, S.121. Zu den Problemen, die die kriegerischen und missionarischen Unternehmungen in Südamerika der katholischen Kirche stellten, z.B. wie ein eigenständiger Klerus in ethnisch und kulturell sehr unterschiedlichen Gebieten heranzuziehen ist oder wie das katholische Dogma einer völlig unvorbereiteten Hörerschaft zugänglich gemacht werden soll, vgl. C.R. Boxer, The church militant and Iberian expansion, 1440-1770, Baltimore 1978. Im Dienst imperialer spanischer Politik wie der christlichen Fundierung der Universalmonarchie legitimiert Sepúlveda in Auseinandersetzung mit Erasmus den Krieg im Zusammenhang mit der Frage nach menschlicher Freiheit, der Vereinbarkeit aristotelischer und christlicher Ethik, des Besitzes und des weltlichen Engagements des Christen: vgl. H. Mechoulan, L'antihumanisme de J. G. Sepúlveda. Etude critique du «Democrates Primus», Paris 1974; vgl. auch H.M., Raison et alterité chez Fadri- 
fühlende Zentrum Kastilien bildete einen Gegensatz zur stärker am Handel orientierten Peripherie. In der Gesellschaft stellten sich das gewerbetreibende Bürgertum, Handwerker, letrados, die Universitäten sowie Franziskaner und Dominikaner gegen das handeltreibende Großbürgertum und den Adel. Ein Teil der Landbevölkerung bediente sich nur der Gunst des Augenblicks, um die Fesseln der Feudalherrschaft zu lockern. Politisch schließlich bedrohten die Comunidades Privilegien des Patriziats in den städtischen Verwaltungen und suchten eine Begrenzung der königlichen Macht.

In marxistischer Sicht wird das Geschehen von Monika Walter anders gedeutet und ihm eine zentrale Bedeutung für die Bewertung des Humanismus zugeschrieben. Es erscheint als Aufstand der Armen, zu denen besonders die bäuerlichen Kommunen, aber auch besitzlose Landjunker und der untere Klerus zu zählen seien, gegen Stadtbürgertum und König. Das auf Freiheit und Gleichheit gegründete Gesellschaftsideal sei dabei nicht die Verarbeitung humanistischer Gedanken aus den anderen Ländern Westeuropas, sondern „Aktualisierung naturrechtlicher Ideen einer demokratischen Scholastik in Spanien“"45. Die auf der Seite des Kaisers stehenden, zuvor isolierten spanischen Humanisten profitierten insofern vom Aufstand, als sie danach absolutistische Reformbestrebungen und erasmistische Ideen besser durchsetzen konnten. Ihre Kritik stehe in der Tadition der auf gesellschaftliche Mißstände zielenden, volkstümlichen und moralisierenden Literatur, während ihre Utopie vom Goldenen Zeitalter sich mit Erinnerungen an einen realen, aber fehlgeschlagenen Versuch, die Gesellschaft zu verändern, verbinde.

\section{«Armas y letras»}

Nicht mit der bürgerlichen, sondern vor allem mit der adligen Schicht sieht $\mathrm{He}$ len Nader den Humanismus im 16. Jahrhundert verbunden. Die Geschichte der adligen Mendozas auf das 14. Jahrhundert in Kastilien zurückverfolgend, behauptet sie, „that the origins of the Renaissance in Castile were contemporaneous with and independent of the Italian Renaissance" ${ }^{46}$. In ihrer Argumentation schreibt sie dabei dem Grafen von Tendilla, Iñigo López de Mendoza (1442-1515), besondere Bedeutung zu. Die These, Kastilien habe die Werte des Humanismus abgelehnt, da seine Führungsschicht, die hidalgos, am Konflikt zwischen literarischer und militärischer Bil-

que Furio Ceriol. Philosophe politique espagnol du XVI siècle, Paris-Den Haag 1973: Furió Ceriols Ratgeber, vernünftige und angesehene Elitewesen, sollen $\mathrm{HaB}$ und Leidenschaft mit den Mitteln einer nicht auf Theologie, sondern auf Vernunft gestützten Politik zerstreuen.

44 J. Pérez, La révolution des «Comunidades» de Castille (1520-1521), Bordeaux 1970 (span. Übs., Madrid 1978).

45 M. Walter, Die Revolution der Comuneros und die Herausbildung realistischer Literatur in Spanien, in: R. Weimann/W. Lenk/J.J. Slomka (Hrsg.), Renaissanceliteratur und frühbürgerliche Revolution, Berlin-Weimar 1976, S. 67-76 (hier S. 70 f.).

46 H. Nader, The Mendoza Family in the Spanish Renaissance 1350-1550, New Brunswick, New Jersey 1979, S.13. 
dung scheiterte, berücksichtigt nach Nader nicht die Rolle der caballeros und letrados. Letztere behaupten nämlich die Unvereinbarkeit von militärischer und literarischer Bildung nur, um die literarische Bildung den Latein Sprechenden, d.h. sich selbst vorzubehalten. Die caballeros dagegen vertraten die Vereinbarkeit und unterstützten sie durch eigene poetische, historiographische, übersetzerische und bibliophile Tätigkeit ${ }^{47}$.

Es deutet sich hier die vieldiskutierte Schwierigkeit an, zwischen armas und letras, d. h. zwischen militärischer und literarischer Bildung der caballeros, zu vermitteln. Sie geht nach Peter E. Russel auf den antiken, von Ernst Robert Curtius beschriebenen Topos sapientia et fortitudo zurück ${ }^{48}$. Dessen Deutung ausschließlich zugunsten der fortitudo durch eine im 15. Jahrhundert militante und imperiale Ansprüche verfechtende Aristokratie wurde erst in den dreißiger Jahren des 16. Jahrhunderts abgelöst durch die von Garcilaso de la Vega angeregte und von Boscán ausgeführte Ưbersetzung des Cortegiano von Castiglione, in dem militärische und literarische Bildung als gleichwertig gelten.

\section{« Laudes litterarum»}

Zum Lob des Dichters hält Juan Angel González im Jahre 1525 seine stark an italienischen Vorbildern orientierte praelectio an der Universität Salamanca. Er nimmt, wie Juan Alcina Rovira hervorhebt, eine literaturgeschichtliche Darstellung von Autoren vor, nennt die Kenntnisbereiche des poeta eruditus, sieht Dichtung als Typ der Erkenntnis in Verbindung mit den anderen Wissenschaften, stellt Poetik über Rhetorik und betont die soziale Nützlichkeit der Poesie für den Anwalt oder den Höfling ${ }^{49}$. In Reden von Juan de Brocar, Francesc Decio, Juan Pérez, Juan Maldonado und Lope Alonso de Herrera zur Eröffnung der universitären Lehrveranstaltungen sieht auch Francisco Rico die Topik von laudes litterarum und damit verbundener dignitas hominis im Zusammenhang mit den Fächern des Triviums und dem Studium der griechisch-römischen Autoritäten ${ }^{50}$.

47 Vgl. auch G.A. Davies, A poet at court: Antonio Hurtado de Mendoza (1586-1644), Oxford 1971. Zu einem durchschnittlich gebildeten adligen Humanisten, der schriftstellerischen und kriegerischen Ruhm verbindet und sich für die klassische Antike und moderne Entdeckungen begeistert: J. Pérez, Un gentilhomme humaniste: Luis Zapata et sa «Miscelánea », in L'humanisme dans les lettres espagnoles, S. 287-98.

48 P.E. Russel, Las armas contra las letras: para una definición del humanismo español del siglo XV, in: P.E. R., Temas de la «Celestina» y otros estudios. Del "Cid» al "Quijote», Barcelona-Caracas-México 1978, S. 209-39; vgl. E.R. Curtius, Europäische Literatur und lateinisches Mittelalter, Bern-München ${ }^{8} 1973$, S. $182 \mathrm{ff}$.

49 J. Alcina Rovira, Juan Angel González y la «Sylva de laudibus poseos» (1525), Barcelona 1978.

50 F. Rico, "Laudes litterarum»: humanisme et dignité de l'homme dans l'Espagne de la Renaissance, in L'humanisme dans les lettres espagnoles, S. 31-50; zum Wandel des universitären Unterrichts durch den Humanismus: R. Kagan, Students and Society in Early Modern Spain, Baltimore 1974; zur Verurteilung der mittelalterlichen Grammatiker durch die $\mathrm{Hu}$ - 
Angesichts dieser starken humanistischen Prägung des universitären Lebens betont Juan Bautista Avalle-Arce die Bindung der Renaissancebewegung an die Universität: ,„[. . ] el Renacimiento es el verdadero siglo de oro de la universidad española"51.

\section{Poetik und Rhetorik}

Welche Literaturtheorie hat die spanische Renaissance? Nach einem ausführlichen Streifzug durch die Forschungsliteratur macht Karl Kohut einen Systematisierungsvorschlag. Das in der Forschung bis etwa 1970 verbreitete Vorurteil, Spanien habe bis zum Ende des 16. Jahrhunderts keine literarische Theorie, führt er darauf zurück, daß neben den Poetiken, die in der Tat erst ab 1580 zahlreicher werden, nicht auch Rhetoriken, Historiographien, Kommentare und Vorworte berücksichtigt worden seien. Von diesen Quellen ausgehend, kann er in der Literaturtheorie das Fortleben antiken Gedankengutes und die italienischen wie erasmischen Einflüsse zeigen. Eine systematische Betrachtung des Problems, wie sie Kohut vorzeichnet, habe die der Rhetorik nachgebildete Poetik in die Wissenschaftssystematik und die universitäre Praxis einzuordnen. Sie habe auch die Haltung der Kirche, der Humanisten und der Erasmisten gegenüber der heidnischen antiken Literatur und die Folgen des Tridentinums zu berücksichtigen. Von besonderer Bedeutung sei schließlich die Problematik des ,,retraso cultural de España“, der ,Antiguos y Modernos“, ,, armas y letras“. Erst eine derartige Betrachtungsweise mache die Literaturtheorie zu einem Teil des als „fenómeno cultural y social" verstandenen Humanismus ${ }^{52}$.

Die Bedeutung der Poetik des Horaz für die Ausformung der Literaturtheorie in der europäischen Renaissance hebt Antonio García Berrio hervor ${ }^{53}$. Er zeigt, wie diese Poetik im rhetorischen Zusammenhang innerhalb einzelner Gattungen gesehen wird und zur Abgrenzung von res und verba, ingenio und arte, docere und delectare beiträgt. Dabei stellt er fest, daß Spanien die Lehren des Horaz aus Italien unbewußt mitübernommen und benutzt hat ${ }^{53}$.

Auch wenn sich in Spanien die Poetik später verselbständigte als in Italien, war ihr also innerhalb der traditionsreichen rhetorischen Theorie ein, wenngleich meist kleiner, Platz zugewiesen. Die rhetorischen Theorien im 16. und 17. Jahrhundert thematisiert Antonio Martí, wobei er nicht zwischen sakraler und forensischer Rhetorik unterscheidet. Mit Vives, Furió Ceriol, el Brocense u.a. überwiegen in einer ersten Phase der Renaissance die Unabhängigkeit des Urteilsvermögens, das Natür-

manisten von Valla bis zur Zeit von Erasmus: F. Rico, Nebrija frente a los bárbaros, Salamanca 1978.

51 J.B. Avalle-Arce, Aproximaciones al Renacimiento literario español, in: J.B. A., Dintorno de una época dorada, Madrid 1978, S.1-56 (Zit. S. 22).

$52 \mathrm{~K}$. Kohut, Las teorías literarias en España y Portugal durante los siglos XV y XVI (Anejos de Revista de Literatura 36), Madrid 1973.

53 A. García Berrio, Formacion de la teoría literaria moderna. La tópica horaciana en Europa, Madrid 1977. 
liche und die zeitgenössische Realität, während mit dem Konzil von Trient die aristotelisch-thomistische Autorität aufs neue bekräftigt und ein größerer moralischer Anspruch erhoben wird ${ }^{54}$. Nach einem Überblick über den Rhetorikunterricht und den Einfluß der Rhetorik auf die Literatur führt José Rico Verdu die wichtigsten rhetorischen Werke des 16. und 17. Jahrhunderts in zusammenfassenden Beschreibungen vor und stellt rhetorische Figuren unter Angabe von Fundstellen in Traktaten und bei zeitgenössischen Schriftstellern zusammen ${ }^{55}$.

\section{Kommentare}

Den Wert des Kommentars als Quelle zur Literaturtheorie erläutert Karl Kohut an vier Beispielen: Hernán Núñez de Toledo wolle 1499 in seinem Kommentar zu Juan de Mena - nach Kohut das erste humanistische Kommentarwerk zu einer volkssprachigen Vorlage in Spanien - den Durchschnittsleser in die Lage versetzen, den Text zu verstehen; zwar beziehe er sich naiv auf antike Musterautoren, werte aber das Studium der Literatur als Wissenschaft auf. Wie Núñez trete Francisco Sánchez de las Brozas in seinen Kommentaren hinter den kommentierten Text zurück, indem er sich auf die Nennung von Quellen und Parallelstellen, die Entschlüsselung mythologischer Anspielungen und textkritische Erörterungen beschränke. Demgegenüber dienten im Kommentar Fernando de Herreras die kommentierten Werke Garcilasos nur als Anlaß für die eigene literarästhetische Reflexion über die Formen der Lyrik, die Imitatio, Metapher, Stil und Schönheit ${ }^{56}$.

Im Gegensatz zu Kohut erscheint María Dolores de Asis der Kommentar des Núñez de Toledo zu Juan de Mena ebenso mittelalterlich wie humanistisch: „, . .] hay también medievalismo en lo que posee de enciclopedia del saber y en la actitud didáctica adoptada por el Comendador“"57. Diesen Charakter führt sie nicht zuletzt darauf zurück, daß Núñez zu jener Zeit gerade Hauslehrer der Söhne des Conde de Tendilla war. Drei Absichten verfolge sein Kommentar: die Stellen, die sich auf die Antike beziehen, durch entsprechende antike „Autoritäten“ zu erläutern, Meinungen seiner Zeitgenossen über neuere historische Ereignisse zu sammeln und auch Stellen als Gelegenheit zur ethischen Ermahnung zu benutzen. Seine rein philologischen Anmerkungen zu Kultismen und Hyperbata, seine Erklärungen von Etymologien, Periphrasen, Apokopen und Textentstellungen in zeitgenössischen Ausgaben bereichert er durch kleine Traktate aus dem Bereich des mittelalterlichen Trivium

54 A. Martí, La preceptiva retórica española en el siglo de oro (Biblioteca Románica Hispánica. Tratados y Monografías 12), Madrid 1972.

55 J. Rico Verdu, La retórica española de los siglos XVI y XVII (Anejos de Revista de Literatura 35), Madrid 1973.

$56 \mathrm{~K}$. Kohut, Der Kommentar zu literarischen Texten als Quelle der Literaturtheorie im spanischen Humanismus. Die Kommentare zu Juan de Mena und Garcilaso de La Vega, in Der Kommentar in der Renaissance, hrsg. A. Buck/O. Herding, Boppard-Bonn 1973, S. 191 bis 208.

57 M.D. de Asis, Hernán Núñez en la historia de los estudios clásicos, Madrid 1977, S. 99. 
und Quadrivium. Dolores de Asis geht auch ausführlich auf Núñez' Beschäftigung mit Seneca, Pomponius Mela und Plinius sowie seine spätere Spruchsammlung ein, die León de Castro mit Berufung auf Erasmus einleitete. Núñez selber bewunderte zwar in seinen späteren Jahren Erasmus als Autor der Adagia, sei aber als Kommentator wohl eher vom „espíritu del tiempo“ beeinflußt. Bezüglich Erasmus „hay que hablar más que de influencia, de coincidencia“"58.

\section{Ưbersetzungen, Bibelausgaben}

Welche antiken Autoren erfuhren die häufigsten spanischen Übersetzungen in welchem Zeitraum? Besonders beliebt waren nach Theodore S. Beardsley vor 1500 Äsop, später, einander abwechselnd Vergil, Apuleius, Ovid, Homer und Plautus. Bemerkenswert ist die steigende Wertschätzung der Muttersprache durch die Úbersetzer $^{59}$. Vittorio Bocchetta vergleicht die Übersetzungen einiger Horazischer Oden durch Fray Luis de León und Manuel de Villegas vor dem Hintergrund zeitgenössischer Ubersetzungstheorien. Die wörtlichere Úbersetzungsweise von Fray Luis de León kontrastiere mit der sinngemäßen, freieren, dadurch aber häufig treffenderen Úbertragung des schon in einer Übergangszeit zum Barock stehenden Villegas ${ }^{60}$. Den unterschiedlichen Arten der Übersetzungspraxis entsprachen unterschiedliche Typen der Úbersetzungstheorie. Vives unterscheidet nach Eugenio Coseriu: ,,a) Úbersetzungen, in welchen ,solus spectatur sensus'; b) solche, in denen ,sola [spectatur] phrasis et dictio“; und c) solche, in denen ,et res et verba ponderantur" "661.

Der humanistische Úbersetzungseifer beschränkte sich nicht auf profane Texte. Auch die Bibel wurde einbezogen. So ließ Benito Arias Montano die Biblia Regia unter der Schirmherrschaft Philipps II. in Antwerpen zwischen 1568 und 1572 durch Plantin drucken. Diese mehrsprachige Bibelausgabe ließ sich von der zwischen 1514 und 1517 in Alcalá de Henares unter der Initiative des Kardinals Cisneros herausgegebenen inspirieren und diente ihrerseits als Vorlage für die Polyglotten, die im 17. Jahrhundert in Paris und London erschienen. Federico Pérez Castro zeichnet die geistesgeschichtliche Bedeutung und L. Voet die praktische und organisatorische Seite des Unternehmens nach. So war die Herausgabe der mehrsprachigen Bibel für Plantin zunächst ein Projekt, das den Verdacht der Heterodoxie von ihm ablenken sollte. Die damit entstandenen Kontakte zu Philipp II. sollten ihm aber später

58 M.D. de Asis, Hernán Núñez, S. 138, 141.

59 T.S. Beardsley, La traduction des auteurs classiques en Espagne de 1488 à 1586 dans le domaine des belles-lettres, in L'humanisme dans les lettres espagnoles, S. 51-64.

60 V. Bocchetta, Horacio en Villegas y en Fray Luis de León, Madrid 1970.

61 E. Coseriu, Zur Sprachtheorie von Juan Luis Vives, in: W. Dierlamm/W. Drost (Hrsg.), Aus der französischen Geistesgeschichte, Heidelberg 1971, S. 234-55 (Zit. S. 246); vgl. auch E. Coseriu, Das Problem des Ubersetzens bei Juan Luis Vives, in Interlinguistica. Sprachvergleich und Ubersetzung. Festschrift zum 60. Geburtstag von Mario Wandruszka, hrsg. K. R. Bausch/H.-M. Gauger, Tübingen 1971, S. 571-82. 
ein Monopol beim Abdruck religiöser Texte sichern, das das Verlustgeschäft der Bibelausgabe ausglich ${ }^{62}$.

Fünf von der Literaturgeschichte weitgehend vergessene Bibelausgaben in spanischer Sprache, die außerhalb Spaniens im 16. Jahrhundert erschienen sind, stellt Enrique Fernández y Fernández vor und zeichnet die Umstände ihres Zustandekommens nach: das Neue Testament von Francisco de Enzinas (1543), die Bibel von Ferrara, ein Kollektiv-Werk, an dem mehrere Generationen mitgearbeitet haben (1553), das Neue Testament von Juan Pérez de Pineda (1556), die Bibel, übersetzt von Casiodoro de Reina (1543) sowie Neues Testament (1596) und Bibel (1602) von Cipriano de Valera. Den sprachgeschichtlichen Wert der Úbersetzungen berücksichtigend, bedauert er, daß außerhalb Spaniens lebenden Humanisten wie Enzinas, der in Cambridge einen Lehrstuhl für Griechisch hatte, und Valera, der in Oxford lehrte, zu wenig Beachtung geschenkt werde ${ }^{63}$.

Einen anderen Bibelübersetzer, den Prediger und Dichter Ambrosio Montesino, stellt Ana M. Álvarez Pellitero vor. Seine Úbersetzung der Vita Christi des Cartuxano werde durch ,preeminencia del texto evangélico, rigor crítico, disposición didáctica“ geleitet $^{64}$. Die Úberarbeitung von Gonzalo García de Santa Marías Evangelios y Epístolas durch Montesino erkläre sich aus der Tatsache, daß schon ein Vierteljahrhundert ausreichte, um ein Werk in sprachlicher Hinsicht veraltet erscheinen zu lassen.

Juan de Valdés' Bibelübersetzung und -kommentar zeigen eine Mischung von neuem Geist und traditioneller Schriftgelehrsamkeit. Bei Fray Luis de León führen die Übersetzung und Exegese biblischer Texte einerseits zu einer Auseinandersetzung mit ,the most complex problems of semantics, lexicography, structure, social and comparative linguistics, and syntactic theory" 65 , andererseits zur Ablösung der mittelalterlichen, dogmatischen Exegese durch eine neue, verstehende Hermeneutik mit jenen Sinnmöglichkeiten, die ein offenes wissenschaftliches Interesse erschließt und die sich aus einem rationalen, konkreten Methodenbewußtsein, der Berücksichtigung der Quellen und der Betonung der individuellen Exegese gegenüber derjenigen der kirchlichen Autorität ableiten. Eine hermeneutische Ausdeutung der mit-

62 F. Pérez Castro/L. Voet, La Biblia poliglota de Amberes, Madrid 1973; vgl. die Bibliographie: B. Rekers, Arias Montano, Madrid 1973 (span. Ubs. der Ausgabe London 1972).

63 E. Fernández y Fernández, Las Biblias castellanas del exilio. Historia de las Biblias castellanas del siglo XVI, Miami, Florida 1976.

64 A.M. Álvarez Pellitero, La obra lingüústica y literaria de Fray Ambrosio Montesino, Valladolid 1976, S. 272.

65 C.G. Noreña, Fray Luis de León and the Concern with Language, in: C.G.N., Studies in Spanish Renaissance Thought (Archives Internationales d'Histoire des Idées 82), Den Haag 1975, S.150-209 (Zit. S. 199). Zu den traditionellen Elementen vgl. die Einleitung zu Fray Luis de León, De los nombres de Cristo, hrsg. C. Cuevas García, Madrid 1980 (S.13 bis 134), S. $86 \mathrm{ff} . ;$ zu Valdés vgl. M. Morreale, Juan de Valdés, traducteur de la Bible: théorie et pratique à travers la version du Psaume 17(18), in L'humanisme dans les lettres espagnoles, S. 65-88; vgl. allgemein: K. Reinhardt, Die biblischen Autoren Spaniens bis zum Konzil von Trient, Salamanca 1976. 
telalterlichen Schriftsinne wie die diversitas der Erkenntnismöglichkeiten, die nicht mehr dem göttlichen Prinzip, sondern dem philologischen Instrumentarium des Exegeten zugeordnet wird, findet Karl Hölz in Fray Luis de Leóns poetischem Werk, seinen Schriften zur Übersetzung wie seinen Auseinandersetzungen mit der Inquisition. Sie weisen über Fray Luis hinaus in eine Art Daseinshermeneutik des 17. Jahrhunderts, deren Leitbegriffe equívoco, engaño und obscuritas wurden ${ }^{66}$.

\section{Sprachreflexion}

Reflexion über sprachliche Fragen mußte an Bedeutung gewinnen, da sie sich im 16. Jahrhundert mit der Ausbildung der Nationalstaaten und -literaturen verbindet ${ }^{67}$. Sie wird nach Werner Bahner von einem nationalen Bewußtsein begleitet, das zahlreiche Intellektuelle an der Sprachdiskussion teilnehmen läßt:

Il y eut une fusion de la philologie, de la littérature, de l'historiographie et de l'histoire de la langue dans les limites de la science de cette époque ${ }^{68}$.

Sprachgeschichtliche und etymologische Forschungen, Aufweis von Verwandtschaftsbeziehungen, auch auf morphologischer Basis, zwischen dem Spanischen und dem Italienischen sowie die These von der natürlichen Entwicklung der Sprachen lassen die Bedeutung jener Zeit für die Geschichte der Sprachwissenschaft in Spanien erkennen.

Zahlreiche Informationen über Gebrauch und Bewertung des Kastilischen gegenüber dem Lateinischen und Italienischen, je nach geographischer und sozialer Situation in Verbindung mit patriotischer Begeisterung oder heftiger Kritik, z.B. am Verfall der Lateinkenntnisse im spanischen Bildungsleben, gibt Dietrich Briesemeister. Er zeichnet die zweihundertfünfzigjährige Vorgeschichte des Sprachbewußtseins Nebrijas nach, das sprachliche Entwicklung mit nationaler politischer Größe verknüpft ${ }^{69}$.

66 K. Hölz, Im Banne des Dogmas. Fray Luis de León und der spanische Humanismus (im Druck).

67 Zum Einfluß der spanischen Sprache in Europa, insbesondere zu den Hispanismen im Italienischen und Französischen vgl. C. Clavería Lizana, España en Europa. Aspectos de la difusión de la lengua y las letras españolas desde el siglo XVI, Madrid 1972 [Discurso Real Academia Española].

$68 \mathrm{~W}$. Bahner, La philologie romane et les problèmes linguistiques de la renaissance, BRPh. 13 (1975) S. 211-16 (Zit. S. 214); vgl. auch W.B., Beitrag zum Sprachbewußtsein in der spanischen Literatur des 16. und 17. Jahrhunderts, Berlin 1956.

D. Briesemeister, Das Sprachbewußtsein in Spanien bis zum Erscheinen der Grammatik Nebrijas (1492), in Iberoromania 1 (1969), S. 35-55. Zur Beziehung zwischen translatio imperii und translatio linguae bei Nebrija, zum Verhältnis zwischen Wissenschafts- und Herrschaftssprache, zur Einschätzung des Spanischen gegenüber dem Lateinischen nach den Kriterien von usus und ars sowie zur höheren Bewertung politischer Fragen gegenüber sprachlichen vgl. H. Weinrich, Das spanische Sprachbewußtsein im Siglo de Oro, in Spanische Literatur im Goldenen Zeitalter, S. 524-47; vgl. auch allgemeiner: G. A. Padley, Grammatical Theory in Western Europe 1500-1700. The Latin Tradition, Cambridge 1976. 
Das Bild einer komplexen Sprachtheorie, das sich aus Teilen der unterschiedlichen Schriften von Vives ergibt, stellt Eugenio Coseriu zusammen. Vives, der die Sprache einerseits als Ausdruck des menschlichen Bewußtseins, andererseits als Instrument des Zusammenlebens versteht, interessiere weniger die Sprache als Abstraktum als die Vielfalt der Einzelsprachen, die er als Schatzkammer der eruditio schätzt. Die Grammatik habe dem Sprachgebrauch zu folgen, ihn nicht vorzuschreiben. Seine Zeichentheorie bezieht die Geltung der Zeichen auf jeweilige Empfänger und unterscheidet zwischen der Bedeutung im eigentlichen Sinn und assoziativer Evokation. Dem sensus communis folgend, binde Vives die Funktion der Wörter in konkrete Situationen des Sprechens ein und wolle schließlich nicht nur die Grammatik,

sondern auch die Rhetorik und die Dialektik (Logik) auf den Sprachgebrauch zurückführen und sie als Wissenschaften des Sprachgebrauchs in einer bestimmten Einzelsprache ansehen $^{70}$.

Dieser Versuch rückt ihn in die Nähe moderner "Ordinary Language Philosophy“. Dennoch, so hebt Richard Waswo hervor, gehe Vives nicht so weit wie Lorenzo Valla ${ }^{71}$.

Die im Mittelalter für unantastbar gehaltene Ưbereinstimmung von Wort, Gegenstand und Bedeutung ist aufgelöst - eine Auflösung, die man, bei Juan de Valdés 1535 beginnend, im Namen von ingeniosidad und sutileza zum literarischen Stilmittel erhoben findet ${ }^{72}$. Die Beziehung von Gegenstand und Bezeichnung ist nach Mark D. Johnston auch ein Thema des Jardin de flores curiosas. Dort scheint der adäquate Ausdruck weitgehend unbekannter kosmographischer Objekte, der nicht durch empirische Forschung und nur mühsam durch Lektüre zu erarbeiten ist, am besten im Dialog, in der Konversation gefunden werden zu können ${ }^{73}$.

70 E. Coseriu, Zur Sprachtheorie von Juan Luis Vives, S. 250.

71 R. Waswo, The Reaction of Juan Luis Vives to Valla's Philosophy of Language, BHR 42 (1980) S. 595-609; Vgl. dazu R.W., The "Ordinary Language Philosophy» of Lorenzo Valla, BHR 41 (1979) S. 255-71.

72 H. Baader, El equívoco. Die Uneindeutigkeit als Stil- und Strukturprinzip der spanischen Literatur des Goldenen Zeitalters, in Spanische Literatur im Goldenen Zeitalter, S.12-39 (bes. S. 26).

73 M.D. Johnston, La retórica del saber en el «Jardin de flores curiosas» de Antonio de Torquemada, JHPh. 3 (1978) S. 69-83; zur Torquemadas Briefsteller Manual de escribientes, in dem es um Normen der alltäglichen Interaktion geht, vgl. die von M.J.C. de Zamora und A. Zamora Vicente besorgte und eingeleitete Ausgabe (Anejos del Boletín de la Real Academia Española 21), Madrid 1970. Inwiefern Sprache im alltäglichen Umgang von Vives, Guevara und Gracián Dantisco in einen ,pragmalinguistischen“ Rahmen gestellt wird, zeigt sich, wenn man analysiert, wie bei ihnen der Sprecher und seine Gesprächspartner gesehen, welche Redehäufigkeit empfohlen, und wie Lüge, Schmeichelei, üble Nachrede und Spott eingeschätzt werden: Ch. Strosetzki, Sprache als Handlung in der spanischen Renaissance, in Wolfenbütteler Renaissance-Mitteilungen 5 (1981) S. 43-49. 


\section{Humanisten und Mediziner: Villalón, Mexía, Servet, Huarte}

Joseph J. Kincaid sieht in Cristóbal de Villalón den Autor der anonym erschienenen Texte El Scholástico und Viaje de Turquía, beides Werke, die im Geist des erasmischen Humanismus stehen ${ }^{74}$. Ohne Erasmus $\mathrm{zu}$ nennen, verteidige Villalón in seinem Scholástico die humaniores litterae mit Argumenten aus Erasmus' Antibarbari, sei also auch - hier korrigiert Bataillon eine eigene frühere Ansicht erasmistisch ${ }^{75}$.

Die Coloquios von Pedro Mexía gehören nach Antonio Castro Díaz zur humanistischen Gattung des Dialogs. Dieser porträtiere im Vergleich zu dem antiken die Charaktere stärker psychologisch. Er hebe in seiner erasmistischen Ausprägung christliche Werte stärker hervor als der eher an Form und Bildungselementen orientierte italienische Dialog. Daneben werden in der Studie von Castro Díaz die Korrespondenz Mexías mit Erasmus sowie Struktur, Inhalt und Quellen seiner Coloquios dargestellt $^{76}$.

Miguel Servet wird von José Barón Fernández als Arzt, Entdecker des Blutkreislaufs, Naturwissenschaftler und Herausgeber von Bibeltexten mit seiner mystischen Auffassung der Christusgestalt und seiner schriftgetreuen Interpretation theologischer Prinzipien vorgestellt ${ }^{77}$.

Juan Huartes Rezeption und Wirkung auf die Diskussion um den Geniebegriff in Deutschland hat Martin Franzbach verfolgt ${ }^{78}$. Seiner Wirkung in Frankreich ist $\mathrm{Ga}$ briel A. Pérouse nachgegangen, der ferner in einem Artikel über den Examen die Rolle der natürlichen Begabung bei der Ausbildung der individuellen Fähigkeiten betont, die den sozialen Status bedingen ${ }^{79}$. Ähnlich beleuchtet Carlos G. Noreña die somatische Basis des Huarteschen ingenium, seine Nutzbarmachung zur Vergrößerung der allgemeinen sozialen Wohlfahrt durch Erziehung, genetische und diätetische

74 J.J. Kincaid, Cristóbal de Villalón, New York 1973.

75 M. Bataillon, Héritage classique et culture chrétienne à travers «El Scholástico» de Cristóbal de Villalón, in L'humanisme dans les lettres espagnoles, S.15-29.

76 A. Castro Díaz, Los «Coloquios» de Pedro Mexía, Sevilla 1977.

77 J. Barón Fernández, Miguel Servet, Madrid 1970; vgl. auch R.H. Bainton, Servet, el hereje perseguido, Madrid 1973 (Boston 1953); F. Sánchez-Blanco, Michael Servets Kritik an der Trinitätslehre: Philosophische Implikationen und historische Auswirkungen, Frankfurt/M.Bern-Las Vegas 1977; J. Friedman, Michael Servetus. A Case Study in Total Heresy, Genf 1978.

78 M. Franzbach, Lessings Huarte-Ubersetzung (1752). Die Rezeption und Wirkungsgeschichte des «Examen de ingenios para las ciencias» (1575) in Deutschland (Hamburger Romanistische Studien: B, 29), Hamburg 1965.

79 G. A. Pérouse, L'Examen des Esprits du Dr. Huarte de San Juan. Sa diffusion et son influence en France aux XVI et XVII siècles, Paris 1970; G.A.P., Le Dr. Huarte de San Juan: Pédagogie et politique sous Philippe II, BHR 32 (1970) S. 81-92; Mehnert will ,als noch weniger beachtetes Differenzierungskriterium zwischen Renaissance- und Barockästhetik Aspekte einer gewandelten Genielehre" herausstellen: H. Mehnert, Der Begriff «ingenio» bei Juan Huarte und Baltasar Gracián. Ein Differenzierungskriterium zwischen Renaissance und Barock, RF 91 (1979) S. 270-80 (Zit. S. 272). 
Lehren und die Folgen für moralisches Verhalten, Freiheit und Gnadenlehre ${ }^{80}$. Huartes somatische Lehren greifen nicht nur in Bereiche der Moral und Theologie, sondern auch in jene der Sprache und Ästhetik: Sprache als Fähigkeit des entendimiento auf der einen Seite, Stilistik, Poesie und Redekunst als Fähigkeiten von imaginativa und memoria auf der anderen, bilden nach Esteban Torre die psychobiologische Basis für Huartes Reflexionen zur Sprache als Instrument des Denkens, der Kommunikation und des ästhetisch schönen Ausdrucks ${ }^{81}$.

Die bei Huarte deutlich gewordene Verbindung zwischen Medizin und Geistesgeschichte ist auch im weiteren Rahmen der allgemeinen Wissenschaftsgeschichte mit Gewinn zu verfolgen. Der Medizinhistoriker José María López Piñero bezieht das von ihm vorgestellte breite Panorama naturwissenschaftlicher Forschung, Publikation und Lehre auf deren Institutionalisierung und Förderung. Dabei geht er aus von der Eingebundenheit des einzelnen Wissenschaftlers, z. B. in einen städtischen oder mittelständischen sozialen Kontext, oder auch von anderen Bedingungen wie dem säkularen oder klerikalen Charakter eines Wissenschaftszweiges oder einer Wissenschaft ${ }^{82}$.

\section{Guevara, Valdés}

Antonio de Guevara wieder in Erinnerung gerufen zu haben, ist Ernest Greys Verdienst. Ihm folgte Joseph $\mathrm{R}$. Jones mit der Darstellung von Leben und Werk dieses Humanisten ${ }^{83}$. Augustin Redondo situiert ihn im politischen und geistigen Leben seiner Zeit als ,,auteur et témoin de son temps“. Er rehabilitiert den auch in den Augen berühmter Hispanisten als Zyniker und Plagiator geltenden Autor in einem opus magnum ${ }^{84}$, dessen umfangreicher Anhangsteil Einblick in Dokumente und Handschriften gestattet und eine umfangreiche Bibliographie mit Fundort und Signatur älterer Schriften bietet. Im Zusammenhang mit ausführlichen biographischen Angaben wird die Geschichte der artes praedicandi verfolgt und die Eigentümlichkeit von Guevaras Predigtkunst herausgearbeitet. Redondo würdigt seine milde Haltung in der Inquisition und seinen Einfluß auf den Generalinquisitor D. Alonso Manrique, seine Arbeiten als offizieller Historiograph, die zwar verlorengegangen sind, deren Spuren man aber bei Santa Cruz und Sandoval finden könne, und schließlich seine Tätigkeit als Bischof von Mondoñedo. Ausführlich geht Redondo. auf zwei Werke Guevaras ein: Marco Aurelio und Relox de príncipes, deren Entstehung und deren Wirkung in Spanien, Portugal, Italien und Frankreich herausgearbeitet wird.

80 C. G. Noreña, Juan Huarte's Naturalistic Philosophy of Man, in: C. G. N., Studies, S. 210-63.

82 J.M. López Piñero, Ciencia y técnica en la sociedad española de los siglos XVI y XVII, Barcelona 1979.

83 E. Grey, Guevara. A forgotten Renaissance Author, Den Haag 1973; J.R. Jones, Antonio de Guevara, Boston 1975; vgl. auch Ch.E. Schweitzer, Antonio de Guevara in Deutschland, RJb. 28 (1977) S. 322-25, als Ergänzung der Bibliographie: RJb. 11 (1960) S. 328-75.

84 A. Redondo, Antonio de Guevara (1480?-1545) et l'Espagne de son temps. De la carrière officielle aux cuvres politico-morales (Travaux d'Humanisme et Renaissance 148), Genève 1976. 
Außerdem geht er den antiken, mittelalterlichen und erasmischen Quellen dieser Werke nach. Die von Guevara vertretenen politischen Ideen der Gesellschaft als „,corps mystique“, der Familie als gesellschaftlicher Keimzelle und schließlich die didaktisch-moralische Zielsetzung der Werke werden hervorgehoben. Dabei betont Redondo Guevaras satirische Kritik an imperialistischer Kriegführung und seine Forderung nach einer Humanisierung des Rechtswesens. Seine Vorstellungen vom christlichen Monarchen bringe Guevara in der Gestalt, die er von dem Stoiker Marc Aurel zeichne, zum Ausdruck.

An anderer Stelle zeigt Redondo, wie die besorgniserregende politische und wirtschaftliche Situation der Jahre 1536-1539 Guevara zur Aufnahme des Horazischen beatus ille bewog, um den verarmt am Hof oder in den Städten lebenden Adligen zur Rückkehr in ihre Ländereien zu raten ${ }^{85}$.

Die Situation Guevaras als Schriftsteller, seine Position im Gegenspiel von armas und letras und in der Wertung von Antikem und Modernem beschäftigt Asunción Rallo Gruss. Sie zeigt den Gegensatz zwischen dem Traditionsverständnis des Grammatikers Pedro de Rúa und Guevaras freiem, spielerischem Umgang mit Zitaten und geschichtlichen Ereignissen, die oft nur dazu dienen, gegenwärtige Verhältnisse widerzuspiegeln. Abstraktes, utopisches Denken zwischen Staatsutopie und ländlicher Idylle stehe bei Guevara ganz konkreten Angaben zur Situation der Frau, der Alten oder des Ärztestandes gegenüber. Guevara habe erkannt, daß das durch den Buchdruck neugewonnene Publikum das Ansehen eines Autors zunächst an seinen Schriften messe. Nach der Darstellung moralistischer, humoristischer und autobiographischer Elemente und narrativer Techniken ordnet Rallo Gruss einzelne Werke in die traditionellen Gattungen des Briefes, der Biographie, des Traktates, des Exempels und der Erzählung ein ${ }^{86}$. Guevaras häufiges Zitieren eines inexistenten antiken Bildungsgutes, auf das auch Rallo Gruss und Redondo hinweisen, läßt R. O. Jones in bezug auf den Arte de marear schließen, daß er sich nicht an ein gebildetes Publikum wendet, das ihn leicht durchschaut hätte, „,but to a public willing to be impressed by learning, but as easy to impress by the appearance of learning as by the real thing " 87 .

Die vielseitige Gestalt des Juan de Valdés hat Bakhuizen van den Brink charakterisiert:

[. . .] érasmien, illuminé, réformateur napolitain, penseur indépendant, esprit original et spéculatif, mystique et en même temps directeur d'âmes par goût et disposition naturelle, psychologue pratique dans le vaste domaine de la religion ${ }^{88}$.

85 A. Redondo, $D u$ «Beatus ille» horacien au «Mépris de la Cour et éloge de la vie rustique» d'Antonio de Guevara, in L'humanisme dans les lettres espagnoles, S. 251-65.

86 A. Rallo Gruss, Antonio de Guevara en su contexto renacentista, Madrid 1979; zu Guevaras modernem novellistischen Konzept der verosimilitud und seiner Bedeutung bei Cervantes: F. Márquez Villanueva, Fray Antonio de Guevara y la invención de Cide Hamete, in: F.M.V., Fuentes literarias cervantinas, Madrid 1973, S. 183-257; vgl. auch L. López Grigera, Algunas precisiones sobre el estilo de Antonio de Guevara, in Studia Hispanica in honorem R. Lapesa, Bd. 3, Madrid 1975, S. 299-315.

87 R.O. Jones (Hrsg.), Antonio de Guevara, "Arte de marear», Exeter 1972, S. XVIII.

88 J.N. Bakhuizen van den Brink, Juan de Valdés, réformateur en Espagne et en Italie, 1529 à 1541, Genève 1969, S. 92. 
José C. Nieto versteht Juan de Valdés vor dem Hintergrund der religiösen Strömungen Spaniens und Italiens im 16. Jahrhundert. Dabei zeigt er, daß Valdés weder durch deutsche oder spanische Mystik noch wesentlich durch Erasmus, noch notwendigerweise durch reformerische Ideen beeinflußt ist. Trotzdem stehe sein theologisches Denken, in dem Gotteserkenntnis und religiöse Erfahrung Schlüsselkonzepte sind, Luther und Calvin nahe, ,,particularmente en su epistemología, la obra de Cristo, la justificación, el lugar de las obras en el esquema de la salvación, y en la antropología“"89. Nachweisen läßt sich jedoch der Einfluß des alumbrado Alcaraz. Persönlichkeit und Werk von Valdés ließen besonders in Italien einen Valdesianismus entstehen, dessen Lehren von der Kirchenreform, vom Bibelverständnis und von der Toleranz sich größerer Beliebtheit erfreuten als jene Luthers ${ }^{90}$.

\section{Vives}

Juan Luis Vives wird in Alain Guys Monographie mit Textauswahl als Kritiker der Scholastik, Erneuerer der Psychologie und Pädagogik und mit seinen Lehren vom Frieden und sozialen Reformen als politischer Philosoph vorgestellt ${ }^{91}$. Ihr voraus geht Carlos G. Noreñas Arbeit, die Vives' intellektuellen Werdegang vor dem Hintergrund der Biographie und zeitgenössischer kultureller Ereignisse erklärt ${ }^{92}$. Die humanistische Wissenschaftskritik sei die Antwort des Exilspaniers jüdischer Herkunft auf enttäuschende Erfahrungen mit dem mittelalterlichen Pariser Wissenschaftsbetrieb in den Jahren 1509-1512. Das Zusammentreffen von Vives mit Erasmus 1517 in Löwen beeinflusse seine Augustinuskommentare, wie seine Korrespondenz mit ihm Vives' Rolle in der Strömung des spanischen Erasmismus beleuchte. Seine Erziehungsideale sowie seine sozialreformerischen, europäischen und pazifistischen Ideen stünden in der Tradition des flämischen und englischen Humanismus und spiegelten Vives' persönliche Freundschaft mit verschiedenen Humanisten wider. Der Bruch mit dem englischen Hof ermögliche die ungestörte Arbeit an einer wegweisenden, auf introspektiver Beschreibung menschlicher Handlungen gründenden Psychologie. Vives' eklektizistische Lehre ließe sich trotz zahlreicher Widersprüche als Wissenskonzeption im Sinne einer christlich verstandenen Stoa erkennen: Wissen sei gottgegebenes Instrument zur moralischen Verbesserung. Daher haben gesellschaftsreformerische Ideen beim einzelnen Individuum anzusetzen.

Der 6. Congreso Internacional de Estudios Clásicos (Madrid 1974) ehrte Vives mit sechs Vorträgen ${ }^{93}$. Unter dem Titel Luis Vives y el Renacimiento en España

89 J. C. Nieto, Juan de Valdés y los orígenes de la reforma en España e Italia, México-MadridBuenos Aires 1979, S. 527 (erweitert nach der englischen Ausgabe, Genf 1970).

90 Zu Struktur, Stil, Erzähltypen, Modernität des offenen Schlusses und literarischen Verwandtschaften des Diálogo vgl. J.B. Avalle-Arce, La estructura del "Diálogo de la lengua », in: J.B.A., Dintorno de una época dorada, S. 57-72.

91 A. Guy, Vivès ou l'humanisme engagé, Paris 1972.

92 C.G. Noreña, Juan Luis Vives, Den Haag 1970.

93 Homenaje a Luis Vives. Ponencias leídas en el VI Congreso Internacional de Estudios Clásicos celebrados en Madrid del 2 al 6 de Septiembre de 1974 (Fundación Universitaria Española 20), Madrid 1977. 
würdigt Pedro Sainz Rodríguez die Forschungsliteratur zu Vives, unterstreicht die aus Vives' jüdischer Herkunft und seiner Begegnung mit Ignatius abzuleitenden Einstellungen und versteht ihn vor dem Hintergrund der Diskussion um die Existenz einer spanischen Renaissance als ,uno de aquellos espíritus en los cuales la Edad Media se prolonga a través del Renacimiento“94. Vives' Latein sieht Antonio Fontán in der erasmischen anticiceronianischen Strömung, unterscheidet aber je nach Textart unterschiedliche Stiltypen. Das Wort „Ciceronianismus" will Fidel Arbudo Sánchez in seinem Beitrag ersetzt wissen durch den Ausdruck ,,humanismo ciceroniano", der Cicero nicht nur als stilistisch-sprachliches, sondern auch als politischethisches Vorbild versteht. Ciceros Somnium Scipionis und Vives' Kommentar dazu erscheinen Louis J. Swift als Beispiel für die praktischen und ethischen Lehren, die Vives über die sprachlich-stilistischen hinaus aus der Antike ziehen will. Den Wandel der Einschätzung von Vives durch Erasmus verfolgt Adolfo Etchegaray Cruz. José Jiménez Delgado nennt Gründe für die geringe Bekanntheit von Vives' Korrespondenz und verweist auf Ergebnisse seiner Forschungen, die eine erheblich größere Zahl von Briefen zugänglich zu machen versprechen.

Eine weitere internationale Tagung mit 14 Vorträgen über das Werk von Vives fand 1980 unter der Leitung von August Buck in Wolfenbüttel statt ${ }^{95}$. In seinem Eröffnungsvortrag Vives' Konzeption des humanistischen Gelehrten hat Buck Vives' Geschichtsbewußtsein und Selbstverständnis gegenüber der Antike hervorgehoben. Der Traktat De tradendis disciplinis mit seiner Schlußbetrachtung De vita et moribus eruditi zeige die ethische Fundiertheit seines Wissenschaftsbegriffs und seine Abwertung einer bloß stilistische Fertigkeit betonenden Rhetorik, die nicht zu den Inhalten der Philosophie oder den Gegenständen eines eruditus bzw. doctus vordringt. Der ethischen Fundiertheit des Wissenschaftsbegriffs entspreche die Forderung moralischer Integrität und Askese in der vita des Gelehrten, der sich im Gedankenaustausch mit Gleichgesinnten, in einer Art Gelehrtenrepublik, zu verstehen habe. Angesichts der Unzuverlässigkeit der meist benutzten, von Mayans herausgegebenen Vives-Gesamtausgabe erläutert Jozef Ijsewijn Probleme einer textkritischen Edition der Werke Vives' "Triumphus Christi» und "Ovatio Mariae». Eine der Pädagogik untergeordnete Literaturtheorie und Literaturkritik bei Juan Luis Vives führt Karl Kohut vor, indem er Vives' moralisierende Bewertung der Literatur als philosophisches Problem zwischen Wahrheit und Lüge einordnet und als Bestandteil der Rhetorik faßt. In literaturgeschichtlicher Perspektive geht Edward V. George Lubbock der Imitatio in the Somnium Vivis nach. Der Ästhetik als kreativem Prinzip zuzuordnen ist auch Der «ingenium»-Begriff bei Vives, den Emilio Hidalgo Serna als Vermögen der Intuition, des Verstehens und des Beurteilens der bloßen Gedächtnisleistung gegenüberstellt. Damit steht das ingenium in engem Zusammenhang mit der Pensée anthropologique de J. L. Vives: L'Entéléchie, die Mario Sancipriano im Rück-

94 Homenaje, S. 24.

95 Juan Luis Vives, Arbeitsgespräch veranstaltet vom Forschungsprogramm der Herzog August Bibliothek in Zusammenarbeit mit dem Wolfenbütteler Arbeitskreis für Renaissanceforschung, vom 6. bis 8.11.1980, unter Leitung von August Buck (Wolfenbütteler Abhandlungen zur Renaissanceforschung 3) Hamburg (im Druck). 
griff auf Aristoteles erläutert. Vives' soziale Bemühungen, die sich zwischen frommer wohltätiger Linderung des auf den Sündenfall zurückzuführenden Übels der Armut auf der einen Seite und der geradezu revolutionären Organisation öffentlicher Armenpflege auf der anderen bewegen, thematisiert Robert Stupperich als Das Problem der Armenfürsorge bei Vives. Vives' sozialen Vorstellungen steht allerdings die Tatsache gegenüber, daß er einen juristisch nur wenig geschulten Sachverstand hatte, wie Constant Matheeussen, ausgehend von der Betrachtung des Aedes Legum, darlegt: als Philosoph erwarte Vives die Beseitigung möglicher Entartungsgründe der Gesetze, ihre Übertragung in die Volkssprachen und die Möglichkeit ihrer Konsultation. Miquel Batlloris Abhandlung über Joan-Lluís Vives in der Geschichte der aragonisch-katalanischen Renaissance stellt Vives' im Exil europäisch geprägten Humanismus humanistischen Strömungen seiner iberischen Heimat gegenüber. Vives' Rezeption in Italien betrachtet Agostino Sottili, in England Claus Uhlig, und in Deutschland anhand der gedruckten deutschen Ưbersetzungen seiner Werke im 16. Jahrhundert Dietrich Briesemeister. Während Charles Fantazzi den europäischen Humanismus in den Beziehungen von Vives, More and Erasmus erörtert, geht es JeanClaude Margolin um das Europäische im Denken von Vives: Conscience européenne et réaction à la menace turque d'après le «De dissidiis et bello turcico» de Vives.

So zeigen die Studien zum Werk von Vives, die wir mit Bedacht ans Ende dieses Berichts gestellt haben, noch einmal die enge Verflechtung des spanischen Humanismus mit dem gesamteuropäischen Phänomen von Humanismus und Renaissance. Sie bestätigen die Vielfalt der Fragestellungen und lassen besonders deutlich die Fülle der Aufgaben erkennen, die sich der Forschung auf dem Gebiet des Humanismus und der Gelehrsamkeit im Spanien des 16. Jahrhunderts noch stellen.

Düsseldorf, im September 1981 